\title{
Differences in Body Composition of Upper and Lower Limbs in Elite Taekwondo Athletes
}

\author{
Diferencias en la Composición Corporal de los Miembros Superiores \\ e Inferiores en Atletas de Taekwondo de Élite
}

MinSoo Jeon'; Anna Jeon² \& Je-Hun Lee ${ }^{3}$

JEON, M.; JEON, A. \& LEE, J. H. Differences in body composition of upper and lower limbs in elite taekwondo athletes. Int. J. Morphol., 38(2): 265-272, 2020.

SUMMARY: In this study, we analyzed the differences in body composition among athletes during different stages of their career Forty taekwondo athletes and 10 non-athletes (20 males and 30 females) with a mean age of 18.2 years (range, 15-23 years), a mean height of $173.4 \mathrm{~cm}$, and a mean body weight of $64.8 \mathrm{~kg}$ were studied using dual energy X-ray absorptiometry and Biodex balance system. The bone mineral density of upper and lower limbs was higher among university athletes of both sexes than in high school athletes. The lean body mass of male athletes in the university was higher than in high school male athletes. By contrast, in case of females, the opposite results were obtained for the upper and lower limbs. Elucidation of the body composition according to career and sex of taekwondo athlete is worthwhile.

KEY WORDS: Taekwondo; Body composition; Upper limb; Lower limb.

INTRODUCTION

Each athlete engaged in various sports may exhibit unique physical traits, which differ from that of a non-athlete (Seo et al., 2015; Noh et al., 2015; Reale et al., 2019). Previous studies reported the differences in body composition among soccer players (Noh et al.). The differences in body composition affect an athlete's performance while other studies report that the association between physical traits and athletic performance is still unknown (Seo et al.).

In taekwondo, the ability to maintain body balance during movement is important, and is directly related to performance (Cha \& Oh, 2016). Studies suggest that elite athletes carry higher lean body mass and lower fat than nonelite athletes (Seo et al.). In relation to physical fitness, factors such as agility, strength, endurance and flexibility are considered very important in taekwondo competition.

Motor coordination including movement, jumping and walking sideways is better among medal-winning taekwondo players than in non-medal winners (Wazir et al., 2019). However these results are predictable. Further information focusing on morphological parameters such as bone mineral density (BMD), spine structure and function is needed for investigation into the differences in performance of young and other athletes. Body composition information facilitates the design of training programs by coaches and indicates the performance potential of an athlete.

Comparison of the body composition between taekwondo athletes at high school and university and the general public and university students or the differences in body composition according to taekwondo career have yet to be reported. Therefore, the purpose of this study was to correlate the body composition of each athlete with performance.

\section{MATERIAL AND METHOD}

Dual-energy X-ray absorptiometry. Forty taekwondo athletes and 10 non-athletes ( 20 males and 30 females) with a mean age of 18.2 years (range, 15-23 years), a mean height of $173.4 \mathrm{~cm}$, and a mean body weight of $64.8 \mathrm{~kg}$ were studied.

\footnotetext{
${ }^{1}$ Department of Sport Science, College of Sports Science, Korea National Sport University, Seoul, Korea.

${ }^{2}$ Department of Anatomy, College of Medicine, Chung-Ang University, Seoul, Korea.

${ }^{3}$ Anatomy laboratory, College of Sports Science, Korea National Sport University, Seoul, Korea.

Minsoo Jeon and Anna Jeon equally contributed to this research.
} 
The body fat, bone mineral content (BMC), lean muscle mass and BMD of upper and lower limbs were calculated using dual-energy X-ray absorptiometry (DXA, Hologic ZDR 4500, USA).

Biodex balance system (Biodex medical system, Shirley, NY). Forty taekwondo athletes (20 males and 20 females) with a mean age of 19.2 years (range, 15-23 years), a mean height of $176.3 \mathrm{~cm}$, and a mean body weight of 67.0 $\mathrm{kg}$ were studied. This study excluded non-athletes from the biodex balance system because the personal status of the general person played a strong role. Among athletes of both sexes, this study measured the stability in stage 6 including the medial-lateral stability index, anterior-posterior stability index and the overall stability index.

In this study, the SPSS 21.0 (SPSS science, Chicago, USA) statistical program was used to identify differences between 5 groups of athletes (high school males, high school females, university males, university females, and general females). Statistical methods included ANOVA, and posthoc Bonferroni correction. The significance level was set at a $P$ value of 0.05 .

\section{RESULTS}

The results of BMD involving the lower limb based on the sex and age of taekwondo players showed statistically significant difference $(\mathrm{F}=20.336, \mathrm{P}<.001)$.

The BMD of all taekwondo athletes was higher than that of the general females (GF). Athletes at university belonging to both sexes showed a higher value than those at high school. Nonetheless, the female athletes in high school showed a higher value than that of the GF (Table I).

The body mass index (BMI) of lower limb in the specimens based on the sex and age of taekwondo players showed a statistically significant difference as follows: Left $(\mathrm{F}=12.919, \mathrm{P}<.001)$, Right $(\mathrm{F}=13.208, \mathrm{P}<.001)$ and Both $(\mathrm{F}=13.446, \mathrm{P}<.001)$.

Table II shows the BMI of lower limb. The BMI of university male athletes (UMA) was higher than that of high school male athlete (HMA), whereas the BMI of high school female athlete (HFA) was higher than that of university

Table I. Bone mineral density (BMD) of lower limb

\begin{tabular}{ccccccc}
\hline \multicolumn{2}{c}{ Factor } & M & SD & F & p & post-hot \\
\hline \multirow{4}{*}{ BMD } & HMA & 1.49 & 0.119 & & & \\
& HFA & 1.41 & 0.061 & & & HMA>HFA, HMA $>$ GF, \\
& UMA & 1.63 & 0.112 & 20.336 & $<.001$ & UMA $<$ HFA, UMA $>$ GF \\
& UFA & & & & & HFA $>$ UFA, HFA $>$ GF, \\
& GF & 1.43 & 0.081 & & & UFA $>$ GF \\
& & 1.23 & 0.070 & & & \\
\hline
\end{tabular}

HMA: high school male athlete, HFA: high school female athlete, UMA: university male athlete, UFA: university female athlete, GF: general female

Table II. Body mass index of lower limb of the specimen [unit: $\mathrm{kg} / \mathrm{m}^{2}$ ]

\begin{tabular}{|c|c|c|c|c|c|c|}
\hline & Factor & M & $\$ D$ & $\mathrm{~F}$ & $\mathrm{p}$ & post-hot \\
\hline \multirow{5}{*}{ Left } & HMA & 12.44 & 1.70 & \multirow{5}{*}{12.919} & \multirow{5}{*}{$<.001$} & \multirow{5}{*}{$\begin{array}{c}\mathrm{HMA}>\mathrm{HFA}, \mathrm{HMA}>\mathrm{GF}, \\
\mathrm{UMA}<\mathrm{HFA}, \mathrm{UMA}>\mathrm{GF}, \\
\mathrm{HFA}>\mathrm{UFA}, \mathrm{HFA}>\mathrm{GF}\end{array}$} \\
\hline & HFA & 12.10 & 1.15 & & & \\
\hline & UMA & 14.59 & 1.934 & & & \\
\hline & UFA & 11.08 & 1.33 & & & \\
\hline & GF & 9.72 & 0.76 & & & \\
\hline \multirow{5}{*}{ Right } & HMA & 12.37 & 1.64 & \multirow{5}{*}{13.208} & \multirow{5}{*}{$<.001$} & \multirow{5}{*}{$\begin{array}{c}\mathrm{HMA}<\mathrm{HFA}, \mathrm{HMA}>\mathrm{GF}, \\
\mathrm{UMA}<\mathrm{HFA}, \mathrm{UMA}>\mathrm{GF}, \\
\mathrm{HFA}>\mathrm{UFA}, \mathrm{HFA}>\mathrm{GF},\end{array}$} \\
\hline & HFA & 12.23 & 0.10 & & & \\
\hline & UMA & 14.69 & 1.91 & & & \\
\hline & UFA & 11.18 & 1.48 & & & \\
\hline & GF & 9.67 & 1.01 & & & \\
\hline \multirow{5}{*}{ Both } & HMA & 24.81 & 3.33 & & & \multirow{5}{*}{$\begin{array}{c}\text { HMA }<\text { HFA, HMA }>\text { GF, } \\
\text { UMA }<\text { HFA,HFA }>\text { UFA, } \\
\text { HFA }>\text { GF }\end{array}$} \\
\hline & HFA & 24.33 & 2.10 & & & \\
\hline & UMA & 29.30 & 3.77 & 13.446 & $<.001$ & \\
\hline & UFA & 22.26 & 2.79 & & & \\
\hline & GF & 19.37 & 1.75 & & & \\
\hline
\end{tabular}


female athlete (UFA). Overall, the BMI of athletes was higher than that of GF.

The results of lean body mass involving lower limb based on sex and age of taekwondo players showed statistically significant differences as follows: Left ( $\mathrm{F}=$ $34.825, \mathrm{P}<.001)$, Right $(\mathrm{F}=31.724, \mathrm{P}<.001)$, and Both $(\mathrm{F}$ $=33.978, \mathrm{P}<.001)$.

Table III shows the lean body mass of lower limb. In the male athlete, the UMA showed a higher value compared with that of HMA. However, the HFA carried a higher value of lean body mass than the UFA. Compared with the GF, athletes also exhibited a higher lean body mass of the lower limb.

The BMC of the lower limb in the specimen based on sex and age of taekwondo players showed statistically significant difference as follows: Left $(\mathrm{F}=24.296, \mathrm{P}<.001)$, Right $(\mathrm{F}=25.883, \mathrm{P}<.001)$, and Both $(\mathrm{F}=25.518, \mathrm{P}<$ $.001)$.

Table IV shows the BMC of lower limb. Among athletes of both sexes, the males showed a higher value than females among university and high school players. Compared with the GF, athletes also showed a higher BMC of lower limb.

Table III. Body lean of lower limb of the specimen [unit: g].

\begin{tabular}{|c|c|c|c|c|c|c|}
\hline & & M & SD & $\mathrm{F}$ & $\mathrm{p}$ & post-hot \\
\hline \multirow{5}{*}{ Left } & HMA & 10444.2 & 1286.1 & \multirow{5}{*}{34.825} & \multirow{5}{*}{$<.001$} & \multirow{5}{*}{$\begin{array}{c}\text { HMA }>\text { UMA,HMA }>\text { UFA, HMA }>\text { GF, } \\
\text { UMA }<\text { HFA, UMA }>\text { GF, HFA }>\text { UFA, HFA }>\text { GF }\end{array}$} \\
\hline & HFA & 8402.7 & 689.8 & & & \\
\hline & UMA & 11663.0 & 1623.9 & & & \\
\hline & UFA & 7743.9 & 818.9 & & & \\
\hline & GF & 6458.7 & 431.1 & & & \\
\hline \multirow{5}{*}{ Right } & HMA & 10392.3 & 1266.1 & \multirow{5}{*}{31.724} & \multirow{5}{*}{$<.001$} & \multirow{5}{*}{$\begin{array}{c}\text { HMA }>\text { UMA, HMA }>\text { UFA, HMA }>\text { GF, } \\
\text { UMA }<\text { HFA, UMA }>\text { GF, HFA }>\text { UFA, HFA }>\text { GF }\end{array}$} \\
\hline & HFA & 8502.5 & 724.7 & & & \\
\hline & UMA & 11756.7 & 1711.9 & & & \\
\hline & UFA & 7806.6 & 931.3 & & & \\
\hline & GF & 6421.4 & 606.6 & & & \\
\hline \multirow{5}{*}{ Both } & HMA & 20836.4 & 2535.9 & \multirow{5}{*}{33.978} & \multirow{5}{*}{$<.001$} & \multirow{5}{*}{$\begin{array}{c}\text { HMA }>\text { UMA,HMA }>\text { UFA, HMA }>\text { GF, } \\
\text { UMA }<\text { HFA, UMA }>\text { GF, HFA }>\text { UFA. HFA }>\text { GF }\end{array}$} \\
\hline & HFA & 16905.1 & 1377.3 & & & \\
\hline & UMA & 23419.9 & 3300.2 & & & \\
\hline & UFA & 15550.7 & 1735.2 & & & \\
\hline & GF & 12879.7 & 1021.2 & & & \\
\hline
\end{tabular}

HMA: high school male athlete, HFA: high school female athlete, UMA: university male athlete, UFA: university female athlete, GF: general female.

Table IV. Bone mineral content of lower limb of the specimen [unit: g]

\begin{tabular}{|c|c|c|c|c|c|c|}
\hline \multicolumn{2}{|c|}{ Factor } & \multirow{2}{*}{$\begin{array}{c}M \\
652.3\end{array}$} & \multirow{2}{*}{$\frac{\boldsymbol{D}}{107.5}$} & \multirow[t]{2}{*}{$F$} & \multirow[t]{2}{*}{$p$} & \multirow[t]{2}{*}{ post-hot } \\
\hline \multirow{5}{*}{ Left } & HMA & & & & & \\
\hline & HFA & 556.9 & 39.4 & & & \multirow{4}{*}{$\begin{array}{c}\mathrm{HMA}<\mathrm{HFA}, \mathrm{HMA}>\mathrm{GF}, \mathrm{UMA}<\mathrm{HFA}, \mathrm{UMA}>\mathrm{GF}, \mathrm{HFA}>\mathrm{UFA}, \\
\mathrm{HFA}>\mathrm{GF}, \mathrm{UFA}>\mathrm{GF}\end{array}$} \\
\hline & UMA & 788.6 & 125.5 & 24.296 & $<.001$ & \\
\hline & UFA & 564.5 & 59.8 & & & \\
\hline & GF & 406.3 & 45.9 & & & \\
\hline \multirow{5}{*}{ Right } & HMA & 651.1 & 92.9 & & & \multirow{5}{*}{$\begin{array}{c}\mathrm{HMA}>\mathrm{UMA}, \mathrm{HMA}>\mathrm{GF}, \mathrm{UMA}<\mathrm{HFA}, \mathrm{UMA}>\mathrm{GF}, \\
\mathrm{HFA}>\mathrm{UFA}, \mathrm{HFA}>\mathrm{GF}, \mathrm{UFA}>\mathrm{GF}\end{array}$} \\
\hline & HFA & 565.4 & 30.8 & & & \\
\hline & UMA & 779.9 & 119.9 & 25.883 & $<.001$ & \\
\hline & UFA & 570.1 & 75.8 & & & \\
\hline & GF & 406.6 & 39.9 & & & \\
\hline \multirow{5}{*}{ Both } & HMA & 1303.5 & 199.9 & & & \multirow{5}{*}{$\begin{aligned} \mathrm{HMA}>\mathrm{HFA}, \mathrm{HMA}>\mathrm{GF}, \mathrm{UMA}<\mathrm{HFA}, \mathrm{UMA}>\mathrm{GF}, \mathrm{HFA}<\mathrm{UFA}, \\
$\[ \mathrm{HFA}>\mathrm{GF}, \mathrm{UFA}>\mathrm{GF} \]$\end{aligned}$} \\
\hline & HFA & 1122.3 & 67.6 & & & \\
\hline & UMA & 1568.5 & 243.8 & 25.518 & $<.001$ & \\
\hline & UFA & 1134.7 & 134.1 & & & \\
\hline & GF & 812.8 & 85.4 & & & \\
\hline
\end{tabular}

HMA: high school male athlete, HFA: high school female athlete, UMA: university male athlete, UFA: university female athlete, GF: general female. 
The BMD of upper limb based on the sex and age of taekwondo players showed a statistically significant difference $(\mathrm{F}=14.365, \mathrm{P}<.001)$.

The BMD of all taekwondo athletes was higher than that of GF. Among the athletes, those in university belonging to both sexes showed a slightly higher value than the high school athletes (Table V).

The BMI of upper limb based on the sex and age of taekwondo players showed a statistically significant difference as follows: Left $(\mathrm{F}=20.190, \mathrm{P}<.001)$, Right ( $\mathrm{F}$ $=19.684, \mathrm{P}<.001)$, and both $(\mathrm{F}=20.796, \mathrm{P}<.001)$.

Table VI shows the body mass of upper limb. In male athlete, the UMA showed a higher body mass than the HMA, whereas the HFA carried a slightly higher level than the UFA. Overall, the female athletes scored higher in body mass than the GF.

The lean body mass of upper limb based on the sex and age of taekwondo players varied statistically significantly as follows: Left $(\mathrm{F}=49.447, \mathrm{P}<.001)$, Right $(\mathrm{F}=42.976, \mathrm{P}$ $<.001)$ and Both $(\mathrm{F}=49.632, \mathrm{P}<.001)$.

Table VII shows the lean body mass of upper limb. Among the male athletes, the UMA scored higher in lean body mass than the HMA. However, among female athletes, the HFA scored higher than the UFA. Athletes also scored higher than the GF in lean body mass.

The BMC of the upper limb of the specimen based on the sex and age of taekwondo players showed statistically significant difference as follows: $\operatorname{Left}(\mathrm{F}=24.450, \mathrm{P}<.001)$, Right $(\mathrm{F}=21.959, \mathrm{P}<.001)$ and Both $(\mathrm{F}=24.297, \mathrm{P}<$ $.001)$.

Table VIII presents the BMC of upper limb. Among athletes of both sexes, the male athletes scored higher than the female athletes at university and high school players. Among both sexes, the university athletes scored higher in BMC than the high school athletes. Athletes also scored higher than the GF.

Table V. Bone mineral density (BMD) of upper limb.

\begin{tabular}{lccccc}
\hline Factor & $\boldsymbol{M}$ & $\boldsymbol{S}$ & $\boldsymbol{F}$ & $\boldsymbol{p}$ & post-hot \\
\hline HMA & 0.93 & 0.075 & & & \\
HFA & 0.85 & 0.047 & & & \\
UMA & 1.01 & 0.062 & 14.365 & $<.001$ & HMA>GF,UMA $<$ HFA, HFA>UFA, HFA>GF, \\
UFA & 0.86 & 0.058 & & & \\
GF & 0.81 & 0.040 & & & \\
\hline
\end{tabular}

HMA: high school male athlete, HFA: high school female athlete, UMA: university male athlete, UFA: university female athlete, GF: general female.

Table VI. Body mass index of upper limb of the specimen [unit: $\mathrm{kg} / \mathrm{m}^{2}$ ].

\begin{tabular}{ccccccc}
\hline \multicolumn{2}{c}{ Factor } & M & D & F & p & post-hot \\
\hline \multirow{4}{*}{ Left } & HMA & 3.57 & 0.543 & & & \\
& HFA & 2.99 & 0.467 & & & HMA $<$ HFA,HMA $>$ UFA, HMA $>$ GF, UMA $<$ HFA, HFA $>$ UFA, \\
& UMA & 4.40 & 0.605 & 20.190 & $<.001$ & HFA $>$ GF, \\
& UFA & 2.77 & 0.469 & & & HMA $>$ UMA,HMA $<$ HFA, HMA $>$ UFA, HMA $>$ GF, \\
& GF & 2.50 & 0.195 & & & UMA $<$ HFA, HFA $<$ UFA, HFA $>$ GF \\
& HMA & 3.74 & 0.646 & & & \\
& HFA & 3.08 & 0.373 & & & \\
& UMA & 4.46 & 0.594 & \multirow{2}{*}{19.684} & $<.001$ & HMA $>$ UMA,HMA $>$ HFA, HMA $>$ UFA, HMA $>$ GF, \\
& UFA & 2.89 & 0.387 & & & UMA $<$ HFA, HFA $>$ UFA, HFA $>$ GF
\end{tabular}

HMA: high school male athlete, HFA: high school female athlete, UMA: university male athlete, UFA: university female athlete, GF: general female. 
Table VII. Body lean of upper limb of the specimen [unit: g].

\begin{tabular}{|c|c|c|c|c|c|c|}
\hline & Factor & M & $\$$ & $\mathrm{~F}$ & $\mathrm{p}$ & post-hot \\
\hline \multirow{5}{*}{ Left } & HMA & 3.57 & 0.543 & \multirow{5}{*}{49.447} & \multirow{5}{*}{$<.001$} & \multirow{5}{*}{$\begin{array}{c}\text { HMA }>\mathrm{UMA}, \mathrm{HMA}<\mathrm{HFA}, \mathrm{HMA}>\mathrm{UFA}, \mathrm{HMA}>\mathrm{GF}, \\
\mathrm{UMA}<\mathrm{HFA}, \mathrm{HFA}>\mathrm{UFA}, \mathrm{HFA}>\mathrm{GF}\end{array}$} \\
\hline & HFA & 2.99 & 0.467 & & & \\
\hline & UMA & 4.40 & 0.605 & & & \\
\hline & UFA & 2.77 & 0.469 & & & \\
\hline & GF & 2.50 & 0.195 & & & \\
\hline \multirow{5}{*}{ Right } & HMA & 3.74 & 0.646 & & & \multirow{5}{*}{$\begin{array}{c}\mathrm{HMA}>\mathrm{UMA}, \mathrm{HMA}<\mathrm{HFA}, \mathrm{HMA}>\mathrm{UFA}, \mathrm{HMA}>\mathrm{GF}, \\
\mathrm{UMA}<\mathrm{HFA}, \mathrm{HFA}>\mathrm{UFA}, \mathrm{HFA}>\mathrm{GF}\end{array}$} \\
\hline & HFA & 3.08 & 0.373 & & & \\
\hline & UMA & 4.46 & 0.594 & 42.976 & $<.001$ & \\
\hline & UFA & 2.89 & 0.387 & & & \\
\hline & GF & 2.63 & 0.224 & & & \\
\hline \multirow{5}{*}{ Both } & HMA & 7.31 & 1.160 & & & \multirow{5}{*}{$\begin{array}{c}\mathrm{HMA}>\mathrm{UMA}, \mathrm{HMA}<\mathrm{HFA}, \mathrm{HMA}>\mathrm{UFA}, \mathrm{HMA}>\mathrm{GF}, \\
\mathrm{UMA}<\mathrm{HFA}, \mathrm{HFA}<\mathrm{UFA}, \mathrm{HFA}>\mathrm{GF}\end{array}$} \\
\hline & HFA & 6.08 & 0.789 & & & \\
\hline & UMA & 8.84 & 1.187 & 49.632 & $<.001$ & \\
\hline & UFA & 5.66 & 0.849 & & & \\
\hline & GF & 5.14 & 0.424 & & & \\
\hline
\end{tabular}

HMA: high school male athlete, HFA: high school female athlete, UMA: university male athlete, UFA: university female athlete, GF: general female.

Table VIII. Bone mineral content of upper limb of the specimen [unit: g].

\begin{tabular}{|c|c|c|c|c|c|c|}
\hline & Factor & M & $\mathrm{D}$ & $\mathrm{F}$ & $\mathrm{p}$ & post-hot \\
\hline \multirow{6}{*}{ Left } & HMA & 193.0 & 31.5 & \multirow{5}{*}{24.450} & \multirow{5}{*}{$<.001$} & \multirow{6}{*}{$\begin{aligned} & \mathrm{HMA}>\mathrm{UMA}, \mathrm{HMA}<\mathrm{HFA}, \mathrm{HMA}>\mathrm{GF}, \\
& \mathrm{UMA}<\mathrm{HFA}, \mathrm{HFA}>\mathrm{UFA}, \mathrm{HFA}>\mathrm{GF}, \\
& \mathrm{UFA}>\mathrm{E}\end{aligned}$} \\
\hline & HFA & 155.7 & 16.6 & & & \\
\hline & UMA & 240.0 & 37.7 & & & \\
\hline & UFA & 159.8 & 22.6 & & & \\
\hline & GF & 124.8 & 9.1 & & & \\
\hline & HMA & 204.4 & 38.4 & \multirow{5}{*}{21.959} & \multirow{5}{*}{$<.001$} & \\
\hline \multirow{4}{*}{ Right } & HFA & 160.6 & 15.6 & & & \multirow{4}{*}{$\begin{array}{c}\mathrm{HMA}>\mathrm{UMA}, \mathrm{HMA}<\mathrm{HFA}, \mathrm{HMA}>\mathrm{UFA}, \\
\mathrm{HMA}>\mathrm{GF}, \mathrm{UMA}<\mathrm{HFA}, \mathrm{HFA}>\mathrm{UFA}, \\
\mathrm{HFA}>\mathrm{GF}\end{array}$} \\
\hline & UMA & 247.9 & 37.2 & & & \\
\hline & UFA & 162.8 & 19.2 & & & \\
\hline & GF & 134.9 & 13.7 & & & \\
\hline \multirow{5}{*}{ Both } & HMA & 397.3 & 69.1 & \multirow{5}{*}{24.297} & \multirow{5}{*}{$<.001$} & \multirow{5}{*}{$\begin{array}{c}\mathrm{HMA}>\mathrm{UMA}, \mathrm{HMA}<\mathrm{HFA}, \mathrm{HMA}>\mathrm{UFA}, \\
\mathrm{HMA}>\mathrm{GF}, \mathrm{UMA}<\mathrm{HFA}, \mathrm{HFA}>\mathrm{UFA}, \\
\mathrm{HFA}>\mathrm{GF},\end{array}$} \\
\hline & HFA & 316.3 & 28.2 & & & \\
\hline & UMA & 488.0 & 74.5 & & & \\
\hline & UFA & 322.7 & 40.9 & & & \\
\hline & GF & 259.6 & 21.1 & & & \\
\hline
\end{tabular}

HMA: high school male athlete, HFA: high school female athlete, UMA: university male athlete, UFA: university female athlete, GF: general female

The analysis of right lower limb using biodex balance system of the specimen based on the sex and age of taekwondo players showed statistically significant differences as follows: Both $\mathrm{F}=3.673, \mathrm{P}=.022$.

The values on the right side of biodex balance system in stage 6 suggest that the HMA (mean 1.54) carried a lower index value than the UMA (mean 1.89) among male athletes, whereas the UFA (mean 1.16) showed a lower index value than the HFA (mean 1.77) in terms of overall stability on the right side. The HMA (mean 1.12) and UFA (mean 0.95) showed a lower index value in the anterior-posterior stability test compared with athletes of the same sex. The HMA (mean 0.93) and UFA (mean 0.61) scored lower index values than the same-sex athletes in medial-lateral stability test (Table IX).

The results of right lower limb using biodex balance system of the specimen based on the sex and age of taekwondo players showed statistically significant 
differences as follows: $\operatorname{Left}(\mathrm{F}=3.411, \mathrm{P}=.028)$ and Both $(\mathrm{F}=7.437, \mathrm{P}<.001)$.

The value on the left side of biodex balance system in stage 6 suggest that the HMA (mean 1.55) scored lower index values than UMA (mean 2.17) among male athletes, whereas the UFA (mean 1.11) showed a lower index value than the HFA (mean 1.43) in overall stability on the right side. The HMA (mean 1.41) and UFA (mean 0.84) showed less index values than same-sex athletes in anterior-posterior stability test. The HMA (mean 0.91) and UFA (mean $0.67)$ exhibited reduced index values than the same-sex athletes on medial-lateral stability test (Table X).

Table IX. The results of right lower limb using biodex balance system .

\begin{tabular}{|c|c|c|c|c|c|c|}
\hline & Factor & $M$ & $S D$ & $F$ & $p$ & post-hot \\
\hline \multirow{4}{*}{ Left } & HMA & 1.54 & 0.47 & \multirow{4}{*}{2.565} & \multirow{4}{*}{.072} & \\
\hline & HFA & 1.77 & 0.81 & & & \\
\hline & UMA & 1.89 & 0.83 & & & \\
\hline & UFA & 1.16 & 0.60 & & & \\
\hline \multirow{4}{*}{ Right } & HMA & 2.367 & .089 & \multirow{4}{*}{2.367} & \multirow{4}{*}{.089} & \\
\hline & HFA & 1.12 & 0.33 & & & \\
\hline & UMA & 1.68 & 1.03 & & & \\
\hline & UFA & 1.23 & 0.53 & & & \multirow{5}{*}{ UMA $>$ UFA, HFA $>$ UFA } \\
\hline \multirow{4}{*}{ Both } & HMA & 0.95 & 0.43 & \multirow{4}{*}{3.673} & \multirow{4}{*}{.022} & \\
\hline & HFA & 3.673 & .022 & & & \\
\hline & UMA & 0.93 & 0.33 & & & \\
\hline & UFA & 1.08 & 0.67 & & & \\
\hline
\end{tabular}

HMA: high school male athlete, HFA: high school female athlete, UMA: university male athlete, UFA: university female athlete.

Table X. The results of left lower limb using boidex balance system of the specimen.

\begin{tabular}{|c|c|c|c|c|c|c|}
\hline & & $M$ & D) & $F$ & $p$ & post-hot \\
\hline \multirow{5}{*}{ Left } & HMA & 1.55 & 0.444 & \multirow{5}{*}{3.411} & \multirow{4}{*}{.028} & \multirow{5}{*}{$\mathrm{HFA}>\mathrm{UFA}$} \\
\hline & HFA & 1.43 & 0.611 & & & \\
\hline & UMA & 2.17 & 1.188 & & & \\
\hline & UFA & 1.11 & 0.328 & & & \\
\hline & HMA & 1.41 & 1.014 & & \multirow{4}{*}{.419} & \\
\hline \multirow{3}{*}{ Right } & HFA & 1.27 & 1.082 & \multirow{3}{*}{.967} & & \\
\hline & UMA & 1.58 & 1.042 & & & \\
\hline & UFA & 0.84 & 0.265 & & & \\
\hline \multirow{4}{*}{ Both } & HMA & 0.91 & 0.102 & \multirow{4}{*}{7.437} & \multirow{4}{*}{.001} & \multirow{4}{*}{$\mathrm{HMA}<\mathrm{HFA}, \mathrm{HFA}>\mathrm{UFA}$} \\
\hline & HFA & 0.94 & 0.114 & & & \\
\hline & UMA & 1.23 & 0.440 & & & \\
\hline & UFA & 0.67 & 0.295 & & & \\
\hline
\end{tabular}

HMA: high school male athlete, HFA: high school female athlete, UMA: university male athlete, UFA: university female athlete.

\section{DISCUSSION}

This study was prompted by concerns of injury involving taekwondo athletes engaged in high kicks or performing sophisticated kicking techniques. It was also motivated by an interest in the differences in body composition according to the career and sex of taekwondo athlete. The comparison of body composition between athletes and general public was investigated before. The BMD and BMC of the cyclist were lower than in control; however, the lean mass was higher than in control (Pimentel et al., 2019). Other research studies reported that the BMD and BMC of nonaquatic athletes such as football players were higher than those of aquatic athletes such as swimmers and both were higher than in controls (Bellver et al., 2019). In this study, the BMD and $\mathrm{BMC}$ of taekwondo athletes of both sexes were higher 
than in controls; however, the differences were greater in the lower than in upper limb. Based on these results, the taekwondo athletes are more likely to use their lower limb and exhibit a greater difference in BMD and BMC compared with controls. As indicated above, the high scores of non-aquatic athletes due to terrestrial exercises appear to result in a greater effect on BMD and BMC. Despite the positive effect of exercise on $\mathrm{BMD}$, it is difficult to correlate between BMD and athlete performance (Alonso et al., 2019).

Among the athletes, the higher body weight seems to suggest a higher BMD (Byun et al., 2015). The BMD among high school participants and university athletes in this study was not analyzed according to body weight. However, in both sexes, the higher BMD of the university athletes compared with the high school athletes affected BMD according to exercise levels. All the athletes who participated in this study were top-ranking players of similar age.

A previous study reported that the BMI of the athletes was lower than that of non-athletes (Pimentel et al.). By contrast, the present study showed that the BMI of lower and upper limbs was higher than in non-athletes. However, no study investigated the effect of BMI on athletic performance. However, a few studies focused on the differences with body weight and age (Byun et al.; Nikolaidis et al., 2016; Reale et $a l$.). Overall, taekwondo athletes of both sexes tended to show an increase in BMI with age as reported previously (Nikolaidis et al.). This study involving female high school athletes' upper and lower limbs showed a higher BMI than in university athletes, whereas in male athletes at the university was scored than the athletes in high school (Table II and 6). These results are contrary to previous reports.

Results of lean body mass involving upper and lower limbs in this study showed that older female athletes scored lower than younger female athletes whereas the opposite was true in males (Tables III and VII). Other studies showed that lean body mass was decreased with age among runners (Alonso et al.); however, in this study only female athletes showed a decrease in lean body mass of upper and lower limbs.

The bilateral balance test demonstrated that male athletes in high school performed better than male athletes in university; however, female athletes at university were better than female athletes in high school. These results are too difficult to explain because all participants were high-ranking athletes.

Among male participants, $16 \%$ of high school athletes and $85 \%$ of university athletes were experienced, which might have influenced the balance test. However, the study limitation relates to the lack of investigation into the extent of injury and current recovery status. In addition, previous animal studies have shown that the ability for balance decreases with age (Silveira et al., 2019), and no such correlation was found in this study. Additional research is needed to analyze the differences between balance and performance, and age and sex in professional athletes.

The factors underlying the higher lean body mass in the UMA than in HMA, and in HFA than in UFA may be related to differences in body weight. The average weights of UMA, HMA, UFA, and HFA were $80 \mathrm{~kg}, 69 \mathrm{~kg}, 59 \mathrm{~kg}$ and $63 \mathrm{~kg}$, respectively. Further analysis into these differences in body weight may elucidate the differences in lean body mass.

JEON, M.; JEON, A. \& LEE, J. H. Diferencias en la composición corporal de las miembros superiores e inferiores en atletas de taekwondo de élite. Int. J. Morphol., 38(2): 265-272, 2020.

RESUMEN: En este estudio, analizamos las diferencias de la composición corporal entre los atletas durante las diferentes etapas de su carrera. Se estudiaron cuarenta atletas de taekwondo y 10 no atletas (20 hombres y 30 mujeres) edad media de 18,2 años (rango, 15-23 años), una altura media de $173,4 \mathrm{~cm}$ y un peso corporal medio de $64,8 \mathrm{~kg}$. Se utilizaron la absorciometría de rayos $\mathrm{X}$ de energía dual y el sistema de equilibrio Biodex. La densidad mineral ósea de las miembros superiores e inferiores fue mayor entre los atletas universitarios de ambos sexos, que en los atletas de educación secundaria. La masa corporal magra de los atletas varones en la universidad fue mayor que en los varones de la educación secundaria. Por el contrario, en el caso de las mujeres, se obtuvieron los resultados opuestos para las miembros superiores e inferiores. En conclusión se debe considerar un análisis de la composición corporal según la carrera y el sexo del atleta de taekwondo.

PALABRAS CLAVE: Taekwondo; Composición corporal; Miembro superior; Miembro inferior.

\section{REFERENCES}

Alonso, A. C.; Ernandes, R. C.; Pereira, R. H. M.; Becker, R. A.; MachadoLima, A.; Silva-Santos, P. R.; Greve, J. M. D. \& Garcez-Leme, L. E. Bone mineral density and body composition in elderly runners: sixyear follow-up. Acta Ortop. Bras., 27(2):92-4, 2019.

Bellver, M.; Del Rio, L.; Jovell, E.; Drobnic, F. \& Trilla, A. Bone mineral density and bone mineral content among female elite athletes. Bone, 127:393-400, 2019.

Byun, W.; Kang, D. \& Hwang, W. A comparative study on bone density and isokinetic muscular strength for each weight division in male rowing athletes. Sport Sci., 32(2):79-83, 2015.

Cha, Y. \& Oh, J. Difference of lower limb, trunk muscle strength, balance ability and proprioception among Korea national taekwondo demonstration player, competition player and trainee. Sport Sci., 33(2):175-84, 2016. 
Nikolaidis, P. T.; Busko, K.; Clemente, F. M.; Tasiopoulos, I. \& Knechtle, B. Age- and sex-related differences in the anthropometry and neuromuscular fitness of competitive taekwondo athletes. Open Access J. Sports Med., 7:177-86, 2016

Noh, J. W.; Kim, M. Y.; Lee, L. K.; Park, B. S.; Yang, S. M.; Jeon, H. J.; Lee, W. D.; Kim, J. H.; Lee, J. U.; Kwak, T. Y.; et al. Somatotype and body composition analysis of Korean youth soccer players according to playing position for sports physiotherapy research. J. Phys. Ther. Sci., 27(4):1013-7, 2015.

Pimentel, R. E.; Baker, B. S.; Soliday, K. \& Reiser 2nd, R. F. Bone mineral density and lean mass asymmetries are greater in cyclists than noncyclists. J. Sports Sci., 37(19):2279-85, 2019.

Reale, R.; Burke, L. M.; Cox, G. R. \& Slater, G. Body composition of elite Olympic combat sport athletes. Eur. J. Sport Sci., 2019. Doi: 10.1080/ 17461391.2019.1616826. In press.

Seo, M. W.; Jung, H. C.; Song, J. K. \& Kim, H. B. Effect of 8 weeks of preseason training on body composition, physical fitness, anaerobic capacity, and isokinetic muscle strength in male and female collegiate taekwondo athletes. J. Exerc. Rehabil., 11(2):101-7, 2015.

Silveira, E. M. S.; Kroth, A.; Santos, M. C. Q.; Silva, T. C. B.; Silveira, D.; Riffel, A. P. K.; Scheid, T.; Trapp, M. \& Partata, W. A. Age-related changes and effects of regular low-intensity exercise on gait, balance, and oxidative biomarkers in the spinal cord of Wistar rats. Braz. J. Med. Biol. Res., 52(7):e8429, 2019.

Wazir, M. R. W. N.; Van Hiel, M.; Mostaert, M.; Deconinck, F. J. A.; Pion, J. \& Lenoir, M. Identification of elite performance characteristics in a small sample of taekwondo athletes. PloS One, 14(5):e0217358, 2019.
Corresponding author:

Professor Je-Hun Lee

Anatomy Laboratory

College of Sports Science

Korea National Sport University

Seoul

KOREA

Email: leejehun@knsu.ac.kr

Received: 16-08-2019

Accepted: 08-10-2019 